\title{
Demand for Meat in the Rural and Urban Areas of Kenya: A Focus on the Indigenous Chicken
}

\author{
H. K. Bett, ${ }^{1,2}$ M. P. Musyoka, ${ }^{3}$ K. J. Peters, ${ }^{1}$ and W. Bokelmann ${ }^{4}$ \\ ${ }^{1}$ Department of Crops and Animal Sciences, Humboldt University of Berlin, Philippstraße 13, Haus 9, 10115 Berlin, Germany \\ ${ }^{2}$ Department of Agricultural Economics and Agribusiness Management, Egerton University, P.O. Box 536, Egerton 20115, Kenya \\ ${ }^{3}$ Department of Regional and Project Planning, University of Giessen, Senckenbergstraße 3, 35390 Giessen, Germany \\ ${ }^{4}$ Department of Agricultural Economics, Humboldt University of Berlin, Philippstraße 13, Haus 12, 10117 Berlin, Germany
}

Correspondence should be addressed to H. K. Bett, hk_bett@yahoo.com

Received 29 March 2012; Revised 26 June 2012; Accepted 30 June 2012

Academic Editor: Almas Heshmati

Copyright (๑) 2012 H. K. Bett et al. This is an open access article distributed under the Creative Commons Attribution License, which permits unrestricted use, distribution, and reproduction in any medium, provided the original work is properly cited.

This study intends to estimate the demand for indigenous chicken meat in Kenya, including other available meat products for comparison purposes. Data used was collected from six counties. A total 930 rural and urban households were sampled. Linear Approximated Almost Ideal Demand System (LA/AIDS) model was used to obtain the demand elasticities and to examine the socioeconomic and demographic factors influencing the meat budget shares. The results ascertain that the socio-demographic factors such as household location, the proportion of household members and the family size are important factors in explaining perceived variations in the consumption of meat products. Indigenous chicken meat, beef and mutton, were identified as necessities. Indigenous chicken meat and beef were identified as substitutes while indigenous chicken, goat and exotic chicken meats were complements. In view of the high expenditure elasticities, therefore, considering a policy option that would enhance consumer income is desirable, since it will result in high consumption thereby providing more incentives for production of meat products. The information generated would be more beneficial to the interest groups in the livestock sector as a whole. This would be utilised in the formulation of effective policies in line with food security and poverty alleviation.

\section{Introduction}

The importance of indigenous chicken (IC) in income generation, improving the nutritional status and food security in rural areas has been widely discussed in various studies in most developing countries $[1,2]$. Unlike other livestock species, IC is widely distributed across most African countries $[3,4]$. Their meat is also preferred by consumers in view of the perception that they are healthier and possess unique attributes such as distinct flavour, leanness, tenderness, and colour [5].

White meat, which includes poultry and pig meats accounts for about 19 percent of the meat, consumed in Kenya locally and for export [6]. The IC contributes 71 percent of the total egg and poultry meat produced and therefore, influencing significantly on the rural trade, welfare, and food security of the smallholder farmers [7]. Moreover, the demand for chicken meat in the urban areas has tremendously increased, consequently raising production of chicken in the rural, urban and periurban areas $[6,8]$. The growth in consumption especially for chicken is to some extent, attributed to its perception as a healthy alternative to red meats besides the low retail prices and ease of preparation [9]. The overall growth in demand for meat would be much accelerated by the surge in human population, rise in incomes, and urbanisation [10-12]. This implies that the rural poor and landless in the developing countries are bound to benefit from the expanded livestock markets and improved household food security, thus alleviating the prevalent protein and micronutrient deficiencies $[13,14]$. Comparatively, the urban poor would be less likely to gain access to better animal source foods (ASF), compared to those in the rural areas. The ASFs are actually easily obtained by the urban rich [15].

Future meat production is expected to be affected by competition of land with the humans. However, this would 
be shaped mainly by the changes in consumption patterns rather than the population growth [16]. Among the livestock species, meat from IC would be the least affected. An analysis done by Costales et al. [17] indicates that at least 25 percent of poultry and pig meats are produced under the landless intensive systems whereas 19 percent and 56 percent being under the land-based extensive and mixed crop-livestock systems, respectively in the sub-Saharan Africa (SSA). Therefore, unlike the ruminants' meat production, the IC enterprises given the current production circumstances, the minimal space requirements for production and the preferences attributed to their products by consumers would therefore be the most suitable and sustainable in meeting the expectations resulting from the rise in demand for meat. Furthermore, it satisfies the two major components of food security, that is, accessibility and availability. However, since most of the IC is produced and consumed within the rural households, their real contribution to the shifts in demand remains unaccounted for due to lack of reliable consumption data. Therefore, the purpose of this study is to examine the pattern of consumption for meat in rural and urban areas of Kenya, however, with an interest in the IC meat. The IC consumption information will therefore facilitate redefining of production schemes and strategies targeting food security and the alleviation of poverty, which is prevalent especially in most of the rural households. In this respect, the estimates on meat demand will assist in providing insights into the appropriate policies for the IC subsector and the livestock sector in general.

1.1. Consumption of Red and White Meat. The poultry sector in Africa largely dominated by chickens has grown rapidly over the years although its future remains uncertain [3]. In spite of that, chicken meat consumption has continuously expanded especially in the sub-Saharan Africa (SSA) [18]. The projected consumption for meat as a whole is expected to be more than double between 1997 and 2025 from 5.5 to 13.3 million metric tonnes in Africa [19]. This increase is partly linked to what is referred to as the "Livestock Revolution" $[13,20]$. However, the overall annual per capita meat consumption is expected at an average of $44 \mathrm{~kg}$ or a total consumption of 326 million metric tonnes of meat in the developing countries by the year 2050 [21]. Moreover, poultry will account for about 40 percent of the global increase in demand for meat by the year 2020, showing a shift in taste from red meat to chicken [22]. Figure 1 shows the trend of meat consumption in Kenya compiled from the FAOSTAT data 2011. The domestic consumption of meat has increased tremendously from 361,115 tonnes in 1991 to 606,169 tonnes in 2007. The per capita consumption of meat was $14.90 \mathrm{Kg}$ in 1991 and rose to $16 \mathrm{Kg}$ in 2007. FAO [23] projected a per capita consumption of $22 \mathrm{~kg}$ by the year 2050 on average for the SSA. According to these statistics, beef is the highest while poultry, fish, and pig meats are the least consumed.

\section{Materials and Methods}

2.1. The Study Area and Sampling Design. The consumption data used in this study comes from the cross-sectional survey

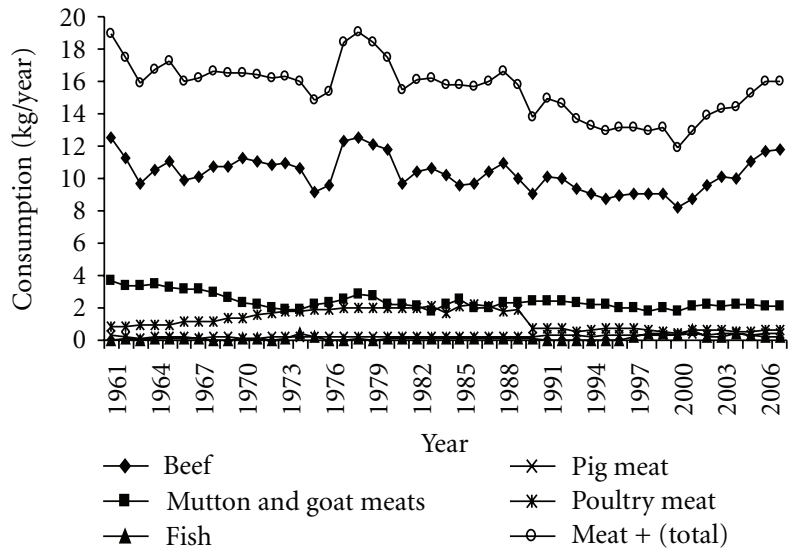

Figure 1: Annual per capita meat consumption in Kenya. Source: FAOSTAT Data [24].

done in selected six counties of Kenya namely, Kakamega, Siaya, West Pokot, Turkana, Bomet, and Narok. This resulted in an interview of respondents from 930 households in the urban and rural areas using structured questionnaires. Pretesting of the questionnaire was done in Nakuru County. The questionnaire captured, demographics, per unit market prices, and consumption expenditure information from the sampled households.

2.2. Demand Systems Analysis Approach. Limited number of studies has been carried out especially concerning the demand for livestock products in Kenya. Analysis of demand has been mainly biased towards the aggregate food items mostly in the urban areas. Williamson and Shah [25] analysed the demand for food products in both the rural and urban areas of Kenya. Recent studies on demand and consumption patterns include [26-28]. Musyoka et al. [28] for instance, examined consumption patterns in urban areas and the implications to urban food security, and Gamba [27] characterized consumption of meat products and eggs in Nairobi city, while Bouis et al. [26] looked at the reliability of food expenditure information from Kenya and Philippines. Moreover, Chantylew and Belete [29] assessed the demand for beef, mutton and goat, pork, and chicken between 1961 and 1991 and demand for sheep and goat meat [30] among others.

Several approaches to estimate demand for livestock meat in general have been utilized in various studies both in the developed and developing countries. There has been use of single equations and systems approach. The systems approach has prevailed over the single equations use since it allows for commodity substitution. We will therefore focus on the systems approach which we eventually apply in this study. Prominently there has been the Linear Expenditure System (LES), the Almost Ideal Demand System (AIDS) and the generalized forms of AIDS and the recent Quadratic AIDS (QUAIDS). Within the systems approach to demand or consumption pattern analysis, the Almost Ideal Demand Model (AIDS) of Deaton and Muellbauer [31] has been the workhouse of the subject. This is because it 
allows for approximate aggregation over consumers while retaining the salient theoretical features of flexibility. Its linear approximate version, the LA/AIDS has been the most popular because of its flexibility, relative ease in estimation and interpretation along with other reasons [32, 33]. Nevertheless, the AIDS has been subject to criticism due to the linearity of Engel curves. This has been the prompt upon which the Quadratic Almost Ideal Demand System (QUAIDS) has been built. Recent studies in SSA and other parts in the developing world which have employed QUAIDS include Abdulai and Aubert [34] and Sheng et al. [35].

Therefore, to examine the demand for meat products, this study assumes the existence of a multistage budgeting where the household first allocates its income based on the total expenses over a broad category of commodities and consequently to the various subgroups of the commodities on the budget on the subsequent stages as described by Edgerton [36]. To allow for imposition of symmetry and homogeneity restrictions consistent to the demand theory, a systems approach was used. Thus, we utilise the LA/AIDS model in estimating the demand for meat products in Kenya.

2.3. Empirical Model Specification. Most studies that have dealt with consumption patterns have assumed a stepwise budgeting process within the household. That is, a household allocates income over broad categories of food and nonfood items, then proceeds further to allocate the respective proportions of income to subcategories. Consequently, at the level which demand analysis is undertaken, the weak separability assumption has to be considered as viable else should be tested. In this study, we assume stepwise budgeting and separability. We consider that meat is a separable subcategory of the food category. Suffice it that our meat consumption pattern analysis is actually at the third stage of the budgeting.

Our empirical model follows the specification of Deaton and Muellbauer, [31] Almost Ideal Demand System. Due to the infrequent consumption or presence of zero purchases of meat products in the data our estimation consists of two stages, in the first stage, we estimate a decision to purchase within a probit model and then estimate an inverse Mills ratio from the probit parameters. This is analogous to Heckman's two-step model used in order to correct for selectivity bias [37]. The approach was first applied within the demand frameworks by Heien and Wessells [38]. The estimated inverse Mills ratios (IMRs) obtained through an estimation of a probit model in the first step are then incorporated in the Almost Ideal Demand System as an instrumental variable in the second stage of the estimation. The socioeconomic and demographic characteristics are also introduced into the budget share equation to capture the differences in tastes and preferences across the households following Pollack and Wales [39] translation approach. The estimable share equation based on the Almost Ideal Demand System demand function is represented as

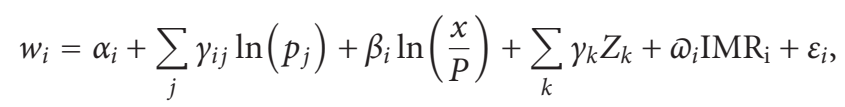

where, $(i, j)$ represents the six meat items, $w_{i}$ is the budget share of the $i$ th meat product derived as $w_{i}=p_{i} q_{i} / x, q$ is the quantity of meat $i$ purchased, $p_{j}$ is the prices of $j$ th and meat, $x$ is the total expenditure of all meat products. The $Z_{k}$ is the demographic and socioeconomic characteristics, $\mathrm{IMR}_{i}$ is the inverse mills ratio, $\varepsilon_{i}$ is the random variable with a zero mean and a constant variance. The $P$ is the Stones Price Index for the aggregate food. The Stone price index was corrected for units of measurement invariance as shown by Moschini [40] and hence was estimated as;

$$
\ln (P)=\sum_{i} \bar{w} \ln \left(P_{i}\right)
$$

where $\bar{w}$ here represents the mean budget share. In order to conform to demand theory, we imposed adding up homogeneity and Slutsky symmetry restrictions as follows:

$$
\begin{aligned}
& \sum_{i} \alpha=1, \\
& \sum_{i} \gamma_{i j}=0, \\
& \sum_{i} \beta_{i}=0, \\
& \sum_{i}{\omega_{i}}=0, \\
& \sum_{i} \kappa_{k i}=0, \quad j=1, \ldots, n \quad \text { (adding up) } \\
& \sum_{k} \gamma_{j k}=0, \quad j=1, \ldots, n \quad \text { (homogeneity) } \\
& \gamma_{i j}=\gamma_{j i} \quad \text { (symmetry). }
\end{aligned}
$$

Moreover, negativity is tested after the estimation of the compensated own price elasticities. Following Green and Alston [41] and Hayes et al. [42], the expenditure elasticity is estimated as:

$$
e_{i}=1+\left(\frac{1}{\bar{w}_{i}}\right)\left(\frac{\partial \bar{w}_{i}}{\partial \log x}\right)=1+\left(\frac{\beta_{i}}{\bar{w}_{i}}\right) .
$$

The Marshallian price elasticities are estimated as

$$
\begin{gathered}
s_{i i}^{M}=-1+\left(\frac{\gamma_{i i}}{\bar{w}_{i}}\right)-\beta_{i} \text { (own-price elasticity) } \\
s_{i j}^{M}=-\delta_{i j}+\left(\frac{\gamma_{i j}}{\bar{w}_{i}}\right)-\left(\frac{\beta_{i j}}{\bar{w}_{i}}\right) \bar{w}_{j}, \\
\forall i, j=1, \ldots, n \text { (cross-price elasticity) }
\end{gathered}
$$

where $\delta_{i j}$ is a Kronecker delta which is equal to 1 , for $i=j$, otherwise zero, while the Hicksian elasticities are obtained from, $s_{i j}^{H}=s_{i j}^{M}+e_{i} \bar{w}_{i}$ and $s_{i j}^{H}=s_{i j}^{M}+e_{i} \bar{w}_{j}$ is as follows:

$$
\begin{aligned}
& s_{i i}^{H}=-1+\left(\frac{\gamma_{i i}}{\bar{w}_{i}}\right)-\bar{w}_{i} \quad \text { (own-priceelasticity) } \\
& s_{i j}^{H}=-\delta_{i j}+\left(\frac{\gamma_{i j}}{\bar{w}_{i}}\right) \quad j=1, \ldots, n \\
& \forall i, j=1, \ldots, n \quad \text { (cross-price elasticity), }
\end{aligned}
$$


The estimation process was carried out through seemingly unrelated regression (SURE). The equation of other meat was dropped to avoid error covariance matrix singularity. The deleted equation is recovered from the imposed restrictions on the LA-AIDS model (1). The SURE systems parameter estimates in this study are obtained by the use of STATA 10.1 [43] econometric software under the constrained iterated seemingly unrelated regression (ITSUR) procedure.

\section{Results}

3.1. Descriptive Results. Table 1 gives details of the variables used in the empirical data analysis. The mean age of the household head was 33.4 years, with an average of 9 years of education. Approximately, 10 percent of the family members were below the age of 14 years and 77 percent were above. The households had an average of five family members. About, 41 percent of the households were in the urban and 59 percent in the rural areas.

The results presented in Table 2 show the expenditures on the meat products. The expenditure allocation and participation rate for the IC meat is the highest among the meat products $[44,45]$, whereas the expense on the Exotic chicken (EC) meat was the least. Beef (BF) and goat (GM) meat had a fair share within the remaining meat types. Besides, the households sampled sometimes or do not purchase the meat products in the other meats (OT) category, which is an aggregation of camel meat, pork, and fish.

\subsection{Empirical Results}

3.2.1. Socioeconomic and Demographic Effects. The maximum likelihood estimates for the socioeconomic and demographic effects and the price and expenditure effects are presented in Tables 3 and 4 . The Chi-squares for all the equations are significant. The $\mathrm{R}^{2}$ for IC, EC, BF, MN, GM and OT are 63.16, 22.22, 52.90, 43.60, 60.22, and 32.60 percent respectively. The poor fit arises from the intermittent purchases of some of the meat products. Few of the selected variables have significant influences on the meat budget shares as shown in Table 3.

Household location (c_loc) significantly influences the shares for IC negatively and positively for ECmeat. The variables hs 1 is negatively significant at $P \leq 0.01$ for only EC and hs 2 at $P \leq 0.05$ for shares allocated to ICand EC meats, although only hs 1 is positively significant for expenditure share of GM at $P \leq 0.05$. In contrast, the IC, BF, and MN equations have significant inverse Mills' ratios. Therefore, ignoring the nonconsumers of these meat categories during the estimation process would result in biased and inconsistent parameter estimates.

3.2.2. Price and Expenditure Effects. Table 4 gives the maximum likelihood estimates for the price and expenditure effects on the budget shares of meat.

Results indicate that the own-price coefficients are positive except for the shares allocated to the other meats (OT).
The own-prices have significant influences on the budget shares for IC meat at $P \leq 0.05$, while at $P \leq 0.01$ for $\mathrm{MN}$ and GM. The own prices for the remaining three categories of meat products are not significant. On the other hand, the expenditure coefficients have a high negative and significant influence on the budgetary allocations for ICandMN, while,for GM is positive at $P \leq 0.01$.

3.2.3. Price, Expenditure Elasticities and Marginal Shares. The own and cross price, expenditures elasticities and marginal shares are reported in Table 5. The price elasticity matrices are comprised of the compensated (Hicksian) and the uncompensated (Marshallian) elasticities. The results indicate that all the Marshallian own price elasticities of the various meat types are negative which is less than zero, hence consistent with the utility theory.

The uncompensated price elasticity for IC, EC, BF, MN and GM are also all negative and are $-0.7705,-0.1089$, $-0.6630,-0.6030$, and -0.6605 respectively. The OT meat category elasticity is -7.5729 , hence very elastic. However, this value is inadmissible hence replaced by “." in Table 5. The aggregation of the meats within this group may have resulted in the high uncompensated and compensated price elasticities in absolute values. The compensated elasticities are all negative. This satisfies the concavity requirement of the utility function implying that the Slutsky matrix also conforms to the negative semidefinite requirement. However, for the disaggregated meat categories, MN has the highest compensated price elasticity or pure price effect, while EC the least. The expenditure on the OT category (2.6917) is the most elastic including GM (1.7619) and EC (1.5020) meats, which are greater than one and so can be regarded as luxury meat types in Kenya. The positive expenditure elasticities on all the meat categories connote that the demand for meats is responsive to the allocated income. Based on this, the null hypothesis of this study is consequently rejected. Additionally, the elasticities are computed using the total expenditure of meat, hence are conditional elasticities. The marginal expenditure shares in our estimated results are calculated by multiplying the estimated expenditure elasticities by the budget shares allocated to each meat category. The marginal shares also sum to one, thus conforming to the adding up condition.

\section{Discussion}

4.1. Demographic, Price, and Expenditure Effects on Budget Shares. The age of the household head and years of education have no significant influences on any of the meat category's budget shares. However, the household location (c_loc) significantly influences the shares for IC negatively and positively for EC meat. This demonstrates that the rural households have higher allocation of their meat budget shares on IC, while the urban on the EC meat category. This can be explained by the unavailability of the EC meat to most of the rural consumers and as well as its difficulty in rearing under the local conditions especially by the poor households. In addition, location has a positive 
TABLE 1: Variable description.

\begin{tabular}{|c|c|c|c|}
\hline Variable & Description & Range & Mean \\
\hline Age & Age of the household head (years) & $17-85$ & 33.40 \\
\hline Educ & Education of the household head (years) & $1-18$ & 9.01 \\
\hline hs1 & Proportion of household members 14 years and below & $0-1$ & 0.09 \\
\hline hs2 & Proportion of the household members 15 years and above & $0-1$ & 0.77 \\
\hline c_loc & 1 if the household is located in the urban area, otherwise rural & $0-1$ & 0.41 \\
\hline hsize & Household size & $1-9$ & 4.71 \\
\hline Lnx_pl & Real meat expenditure & $0.8-9.6$ & 4.99 \\
\hline $\operatorname{Imr}$ & Inverse Mills ratios & & \\
\hline$p 1, p 2, \ldots, p 6$ & Natural logs of prices of IC, EC, BF, MN, GM, and OT meat products, respectively & & \\
\hline
\end{tabular}

TABLE 2: Household meat expenditure.

\begin{tabular}{lccc}
\hline Expenditure meat category & Mean budget shares & Mean expenditure (KES) & Participation rate \\
\hline Indigenous chicken (IC) & 0.6829 & 916.71 & 86.24 \\
Exotic chicken (EC) & 0.0234 & 36.49 & 4.30 \\
Beef (BF) & 0.1354 & 372.93 & 43.66 \\
Mutton (MN) & 0.0336 & 50.21 & 15.27 \\
Goat meat (GM) & 0.0826 & 115.94 & 30.22 \\
Other meat (OT) & 0.0421 & 38.89 & 19.78 \\
\hline
\end{tabular}

$1 \mathrm{US} \$=76 \mathrm{KES}$.

influence on the consumption patterns of the remaining meat types but not significant. A study in rural Bangladesh revealed that place of residence has a modifying effect on meat consumption [46]. Furthermore, it gives substantial explanation of meat consumption patterns since it influences the availability and prices of meat while at the same time reflecting the regional sociocultural and religious differences $[47,48]$.

The proportion of household members is shown to have an effect on the meat budget shares. The negative effects of the proportion of household members of the age 14 years and below and those above 15 years on the budget shares of EC and IC demonstrate that the lower the proportion of the household members within these age groups, the higher the expenditure allocated to the respective meat categories. Conversely, there is a positive effect on the shares allocated to GM and BFby the proportion of members 14 years and below and the 15 years and above, respectively. Moreover, only the portion allocated to GM is reported to increase with a significant decline in the size of the household, implying that more of meat expenditure would be allocated to this category, the smaller the size of the household. Deaton and Muellbauer [49] recognized that the household size has an effect on the consumption of food products in general which mainly vary depending on the composition of the household members. However, a negative effect is expected on meat expenditure shares especially for the highly priced meat products [50]. Conversely, in their study De Silva et al. [48] found a positive influence of the household size on the consumption of the meat products in Sri Lanka. The number of children in the household was identified as the priority determinant influencing the preferences in consumption of meat and meat products. In the present study, the household size effect was insignificant on all of the meat budget share categories, except for GM meat.

The real income or expenditure has a negative and significant influence on the budgetary allocations for ICandMN, while positive for GM. The negative coefficients for IC, BF, and $\mathrm{MN}$ meat shares indicate that the amounts purchased in these categories decline with an income increase. Further, this implies that for those meats which are negative, there is less proportionate increase in consumption as income increases. Moreover, remains unaffected in the EC, GM, and $O T$ categories with the positive coefficients. Changes in real income were also found to have an effect on the meat and fish budget shares in Cameroon [10]. This means that the consumers would reallocate their meat budgets away from $\mathrm{IC}, \mathrm{BF}$, and $M N$ as income increases towards the costly EC, GM, and OT meats.

\subsection{Implications of Price and Expenditure Elasticities on Meat} Consumption Behaviour of the Households. The results indicate that the expenditure elasticities of the various meat categories are all positive and therefore normal commodities. The GM andEC are the most elastic meats categories in the study regions. OT category is also elastic. Indeed this points to that these meat categories are still considered luxurious to meat consumers. This implies that consumption under these categories will more than proportionately increase with an increase in expenditure. The results suggest that the future increases in the consumers' income will consequently favour the consumption of GM and EC meats However, proportionately less will be spent on $\mathrm{MN}$, while on $\mathrm{BF}$ and IC would remain more or less the same. For instance, estimated expenditure elasticity of demand for IC is 0.85 , indicating 
TABLE 3: ML estimates of the household socioeconomic and demographic effects.

\begin{tabular}{|c|c|c|c|c|c|c|c|}
\hline Shares & Age & Educ & hs 1 & hs2 & hsize & c_loc & $\operatorname{Imr}$ \\
\hline \multirow{2}{*}{ IC } & 0.0007 & 0.0010 & -0.0897 & $-0.1075^{* *}$ & -0.0106 & $-0.0913^{* * *}$ & $-0.3561^{* * *}$ \\
\hline & $(0.0012)$ & $(0.0027)$ & $(0.0927)$ & $(0.0767)$ & $(0.0081)$ & $(0.0346)$ & $(0.0299)$ \\
\hline \multirow{2}{*}{ EC } & 0.0007 & 0.0003 & $-0.1335^{* * *}$ & $-0.0674^{* *}$ & 0.0025 & $0.0493^{* * *}$ & -0.0062 \\
\hline & $(0.0006)$ & $(0.0011)$ & $(0.0390)$ & $(0.0339)$ & $(0.0034)$ & $(0.0186)$ & $(0.0189)$ \\
\hline \multirow{2}{*}{ BF } & -0.0007 & 0.0016 & 0.0811 & $0.0866^{*}$ & 0.0073 & 0.0024 & $-0.1167^{* * *}$ \\
\hline & $(0.0008)$ & $(0.0018)$ & $(0.0607)$ & $(0.0507)$ & $(0.0054)$ & $(0.0229)$ & $(0.0343)$ \\
\hline \multirow{2}{*}{ MN } & -0.0006 & -0.0002 & -0.0098 & 0.0045 & 0.0032 & 0.0108 & $-0.0838^{* * *}$ \\
\hline & $(0.0004)$ & $(0.0010)$ & $(0.0344)$ & $(0.0292)$ & $(0.0032)$ & $(0.0127)$ & $(0.0182)$ \\
\hline \multirow{2}{*}{ GM } & -0.0003 & 0.0014 & $0.1004^{* *}$ & -0.0226 & $-0.0120^{* *}$ & 0.0200 & 0.0469 \\
\hline & $(0.0007)$ & $(0.0015)$ & $(0.0521)$ & $(0.0446)$ & $(0.0052)$ & $(0.0195)$ & $(0.0375)$ \\
\hline \multirow{2}{*}{ OT } & 0.0001 & -0.0042 & 0.0514 & 0.1063 & 0.0096 & 0.0087 & 0.5161 \\
\hline & - & - & - & - & - & - & - \\
\hline
\end{tabular}

Standard errors: ${ }^{* * *}$ significant at $1 \%,{ }^{* *}$ significant at $5 \%$, and $*$ significant at $10 \%$.

TABLE 4: ML estimates of the meat categories price and expenditure effects.

\begin{tabular}{|c|c|c|c|c|c|c|c|c|}
\hline \multirow{2}{*}{ Shares } & \multirow{2}{*}{ A } & \multicolumn{6}{|c|}{ Prices } & \multirow{2}{*}{$\beta_{i j}$} \\
\hline & & P1 & P2 & P3 & $\mathrm{P} 4$ & P5 & P6 & \\
\hline \multirow{2}{*}{ IC } & $1.3721^{* * *}$ & $0.0885^{* *}$ & -0.0390 & 0.0020 & -0.0063 & $-0.1037^{* * *}$ & 0.0585 & $-0.0999 * * *$ \\
\hline & $(0.1253)$ & $(-0.0412)$ & $(0.0295)$ & $(0.0272)$ & $(0.0150)$ & $(0.0251)$ & $(0.0399)$ & $(0.0161)$ \\
\hline \multirow{2}{*}{ EC } & 0.0231 & -0.0390 & 0.0211 & -0.0136 & -0.0080 & $-0.0465^{* * *}$ & $0.0859 * * *$ & 0.01175 \\
\hline & $(0.1271)$ & $(0.0295)$ & $(0.0259)$ & $(0.0210)$ & $(0.0160)$ & $(0.0184)$ & $(0.0217)$ & $(0.0135)$ \\
\hline \multirow{2}{*}{$\mathrm{BF}$} & $0.2555^{* *}$ & 0.0020 & -0.0136 & 0.0428 & 0.0110 & -0.0301 & -0.0121 & -0.0209 \\
\hline & $(0.1318)$ & $(0.0272)$ & $(0.0210)$ & $(0.0524)$ & $(0.0195)$ & $(0.0256)$ & $(0.0367)$ & $(0.0155)$ \\
\hline \multirow{2}{*}{$\mathrm{MN}$} & $0.3096^{* * *}$ & -0.0063 & -0.0080 & 0.0110 & $0.0125^{* * *}$ & -0.0018 & $-0.0074^{* * *}$ & $-0.0251^{* * *}$ \\
\hline & $(0.0902)$ & $(0.0150)$ & $(0.0160)$ & $(0.0195)$ & $(0.0271)$ & $(0.0214)$ & $(0.0225)$ & $(0.0103)$ \\
\hline \multirow{2}{*}{ GM } & -0.2269 & $-0.1037^{* * *}$ & $-0.0465^{* *}$ & -0.0301 & -0.0018 & $0.0332 * * *$ & 0.1489 & $0.06295^{* * *}$ \\
\hline & $(0.1391)$ & $(0.0251)$ & $(0.0184)$ & $(0.0256)$ & $(0.0214)$ & $(0.0336)$ & $(0.0327)$ & $(0.0200)$ \\
\hline \multirow{2}{*}{ OT } & -0.7334 & 0.0585 & 0.0859 & -0.0121 & -0.0074 & 0.1489 & -0.2737 & 0.07122 \\
\hline & - & - & - & - & - & - & - & - \\
\hline
\end{tabular}

Standard errors: $* * *$ significant at $1 \%, * *$ significant at $5 \%$, and $*$ significant at $10 \%$.

that a 10 percent increase in the income would increase the demand for IC meat by 8.5 percent, while 8.4 percent for $\mathrm{BF}$ and 15 percent for ECare expected. Moreover, the availability of some of the meat products in the OT category such as camel meat, pork, and fish affects their consumption, but its overall demand would be expected at approximately 27 percent with a 10 percent increase in income. Other factors especially the cultural aspects among some of the urban and rural households were observed to contribute to the acceptance of these products and in particular the consumption of pork. This supports other findings where variations in the culture and beliefs including health factors were identified to be some of the reasons contributing to consumption or avoidance of meat products [44, 45]. Pork in particular is hardly consumed in the households as part of their daily diet in Kenya [29], except by a small group of high-income households [27]. Moreover, camel meat was available to the pastoral communities specifically residing in the rural and urban centers, in some of the parts covered by this study. This reason, and coupled with other factors may have contributed to high magnitudes in absolute terms for the uncompensated and compensated price elasticities of OT, as compared to the rest of the meats, as well as to its very elastic expenditure elasticity. Sheng et al. [51], found similar results for aggregated meat product's category representing the meats exotic to Malaysian consumers. On the contrary, since the $\mathrm{IC}, \mathrm{BF}$, and $\mathrm{MN}$ expenditure elasticities are less than unity then they can be considered as necessities among available meats. Therefore, they are useful in providing essential animal source proteins for the rural and urban consumers in Kenya. In regard to other studies, chicken, beef and mutton were classified as necessities in Bangladesh [52], while only beef in Tanzania [53]. However, beef and the aggregated poultry category were identified as luxuries in urban areas [28], including the aggregated meat category and fish in Cameroon [54] and Tanzania [34]. In South Africa, beef, and mutton were regarded as luxuries while chicken as a necessity [33], similarly beef was a luxury and poultry in contrast was classified as a necessity in Nigeria [55]. In this case, EC, GM, and OT meats are considered luxuries.

Certainly, all uncompensated own price elasticities are negative, and most are less than one, except for the OT share's 
TABLE 5: Price, expenditure elasticities, and marginal shares.

\begin{tabular}{|c|c|c|c|c|c|c|}
\hline Expenditure share category & IC & EC & $\mathrm{BF}$ & $\mathrm{MN}$ & GM & OT \\
\hline & \multicolumn{6}{|c|}{ Marshallian/uncompensated elasticities } \\
\hline Indigenous chicken (IC) & -0.7705 & -0.0536 & 0.0227 & -0.0043 & -0.1398 & 0.0918 \\
\hline Exotic chicken (EC) & -2.0073 & -0.1089 & -0.6479 & -0.3577 & -2.0288 & 3.6486 \\
\hline $\operatorname{Beef}(\mathrm{BF})$ & 0.1202 & -0.0967 & -0.6630 & 0.0864 & -0.2096 & -0.0829 \\
\hline Mutton (MN) & 0.3217 & -0.2197 & 0.4275 & -0.6030 & 0.0088 & -0.1900 \\
\hline Goat meat (GM) & -1.7754 & -0.5810 & -0.4675 & -0.0471 & -0.6605 & 1.7699 \\
\hline \multirow[t]{2}{*}{ Other meats (OT) } & 0.2341 & 2.0011 & -0.5165 & -0.2338 & 3.3963 & $\cdot$ \\
\hline & \multicolumn{6}{|c|}{ Hicksian/compensated elasticities } \\
\hline Indigenous chicken (IC) & -0.1876 & -0.0337 & 0.1383 & 0.0244 & -0.0692 & 0.1277 \\
\hline Exotic chicken (EC) & -0.9817 & -0.0738 & -0.4446 & -0.3072 & -1.9048 & 3.7119 \\
\hline $\operatorname{Beef}(\mathrm{BF})$ & 0.6976 & -0.0769 & -0.5485 & 0.1148 & -0.1397 & -0.0473 \\
\hline Mutton (MN) & 0.4957 & -0.2137 & 0.4620 & -0.5945 & 0.0299 & -0.1793 \\
\hline Goat meat (GM) & -0.5722 & -0.5398 & -0.2290 & 0.0122 & -0.5150 & 1.8440 \\
\hline \multirow[t]{7}{*}{ Other meats (OT) } & 2.0721 & 2.0641 & -0.1521 & -0.1433 & 3.6187 & $\cdot$ \\
\hline & \multicolumn{6}{|c|}{ Expenditure elasticities } \\
\hline & 0.8537 & 1.5020 & 0.8455 & 0.2547 & 1.7619 & 2.6917 \\
\hline & \multicolumn{6}{|c|}{ Marginal shares } \\
\hline & 0.5829 & 0.0352 & 0.1145 & 0.0086 & 0.1456 & 0.1133 \\
\hline & \multicolumn{6}{|c|}{ Income elasticities } \\
\hline & 0.6505 & 1.1446 & 0.6443 & 0.1941 & 1.3427 & 2.0512 \\
\hline
\end{tabular}

category. The EC has the least own price elasticity in absolute terms, implying that, in case of a uniform general price increase in meat, more would be allocated to EC. However, the opposite holds, as it would favour sequentially the shares on OT, IC, and BF. The estimated elasticities for IC and EC meats lie between -0.1089 and -0.7705 therefore are inelastic and fairly compared with the results of Chantylew and Belete [29] with the value of -0.5750 for the aggregated chicken category. Beef, chicken, and mutton were also inelastic in Bangladesh [52]. In essence, if for instance, the price of IC meat falls by 10 percent, then demand would grow by 7.7 percent with the price effect accounting for 1.8 percent while the income effect as a result of the price fall contributing 5.9 percent. Meanwhile, a 10 percent increase in per capita income with a corresponding 10 percent drop in IC meat price would result in a 14.4 percent increase in its demand, given by the addition of 5.9 percent to the corresponding expenditure elasticity in Table 5. This description also applies to the demand for the remaining meat products. Besides that, due to the small magnitudes of the compensated price elasticities for IC and EC, the role of prices is less significant. However, price effects for the other meat products are critical because of their considerable large elasticity magnitudes.

Furthermore, the findings suggest that the meats within the various categories are more of complements than they are substitutes. In most cases, the uncompensated and compensated cross-price elasticities have the same signs except between IC and MN also GM and MN, where the uncompensated and compensated cross-price elasticities are negative and positive, respectively. In this case, the income effect outweighs the substitution effect, rendering $\mathrm{MN}$ an inferior meat product to IC and GM. Thus, indicating that consumers would purchase more of $\mathrm{MN}$ as a result of a price decline. Categorically, the IC meat is identified as a substitute to $\mathrm{BF}$ and the OT meats, while a complement to the rest of the meats. If, for example, the price of IC falls by 10 percent, the demand for $B F$ would decrease by 0.2 percent in Table 5, while 13.8 percent of this decline would consist in the pure price effect. Conversely, for IC complements like GM, a 10 percent reduction in price of IC is associated with an approximately 14 percent rise in demand for GM. Same assessment applies to the other substitutes and complements. In this case, the other estimates suggest that BF substitutes IC and $\mathrm{MN}$, while MN substitutes IC, BF and GM. In addition, EC and GM substitutes OT and are complements to rest of the meat categories. Similarly, Chantylew and Belete [29] identified beef as a substitute for mutton but a complement to aggregated category of chicken meat. Additionally, the South African consumers substituted mutton for chicken and chicken for beef [33]. Moreover, Juma et al. [30] in their study identified that the small ruminants' meat's consumers would not necessarily turn to beef in case of a price rise, but consumption of either product would be based primarily on their preferences. This means, therefore, that consumer preference is crucial in understanding the demand for meat products.

Of all the meat categories, the IC has the highest marginal expenditure share. This implies that, for any future increase in the meat expenditures, the IC will have the highest allocation with a percentage of 58.3 , despite the fact that it is lower than the current share. For this reason, to a certain 
extent would be more welcomed by the poor IC farmers who depend on them for their livelihoods especially in the rural areas. Likewise, expenditures onEC, GM, andOT are expected to grow, with a much smaller allocations on BFandMN meats are expected. According to Deaton and Muellbauer [31], following an increase in income, the value of all additional demands should exactly be equivalent to the value of the additional income. Even though the marginal shares corresponding with EC, GMandOT groups are lower than that of the ICin this study, their high-expenditure elasticities would mean a more significant increase in consumption with an income increase in the future. Other studies in developing countries reveal that the majority of the households' consumption and preferences were on chicken and mutton followed by beef and pork in both the rural and urban areas of Dharwad district in India [56] and the southern province of Sri Lanka [48]. Furthermore, they identified that the growth in expenditure is expected to follow the same pattern, however, would be shaped largely by the nutritive value, taste, tenderness, and availability among other factors.

\section{Conclusion}

The demand estimates in this study are consistent with the economic theory similar to the others studies utilising the AIDS model. The results suggest the existence of different interrelationships among the meat products. There is evidence of substitution between the meat products, with indigenous chicken substituting for beef, while mutton substitutes beef, indigenous chicken and goat meats. Indigenous chicken, beef, and mutton are also necessities among the available meats. Furthermore, the elasticity estimates are necessary in making policies and strategies targeting the meat industry in general in order to improve the national meat production, thereby satisfying the local consumption and obtaining surplus for exports.

These results, therefore, have important implications to policy. Seemingly, household income is likely to have higher impacts on meat consumption than prices. The magnitudes of the former are higher than those of the latter. The current estimates show that policies such as a general price increase in meat intended to assist producers would not have a significant adjustment in the consumers' consumption patterns as those that favour growth in incomes. Initiating income-related policies would mean that consumers would be able to purchase more, in particular exotic chicken, goat meat, and the other meats (OT) which are identified to have high-expenditure elasticities, and hence considered luxuries. However, with an increase in income, meat allocation patterns would fundamentally change with consumers spending more on other meats (OT), exotic chicken and goat meats away from the indigenous chicken meat including beef and mutton. Furthermore, indigenous chicken, widely kept in rural and urban Kenya, are a necessity, and hence play an important role in household diets. Therefore, policy formulation should be careful not to impose taxes on the indigenous chicken meat.

\section{Appendix}

Alternatively, the Income elasticity can be estimated as:

$$
\ln x=\alpha_{0}+\alpha_{1} \ln X+\beta \ln P+\sum_{k} \gamma_{k} H_{k}+\mu,
$$

where $\mathrm{X}$ is the total expenditure on meat products, $X$ is the total expenditures of food and nonfood. The $P$ is the price index for food and $\mu$ is the random variable with zero mean and a constant variance.

\section{Acknowledgments}

The authors are very grateful for grants offered to the first author from the Yousef Jameel Scholarship and Humboldt University of Berlin. They also recognize the inputs from the Kenya Agricultural Productivity Project (KAPP) through the Indigenous Chicken Improvement Project (INCIP) collaboration between Egerton University, Ministry of Livestock Development (MoLD) and Kenya Agricultural Research Institute (KARI).

\section{References}

[1] A. J. Kitalyi, Village Chicken Production Systems in Rural Africa: Household Food Security and Gender Issues, FAO, Rome, Italy, 1998.

[2] F. Moges, T. Azage, and D. Tadelle, Indigenous Chicken Production and Marketing Systems in Ethiopia: Characteristics and Opportunities for Market-Oriented Development, IPMS (Improving Productivity and Market Success) of Ethiopian Farmers Project Working Paper 24, ILRI, Nairobi, Kenya., 2010.

[3] E. F. Gueye, "Production and consumption trend in Africa," World Poultry, vol. 19, pp. 12-14, 2003.

[4] F. O. Ajayi, "Nigerian indigenous chicken: a valuable genetic resource for meat and egg production," Asian Journal of Poultry Science, vol. 4, no. 4, pp. 164-172, 2010.

[5] M. A. Islam and M. Nishibori, "Indigenous naked neck chicken: a valuable genetic resource for Bangladesh," World's Poultry Science Journal, vol. 65, no. 1, pp. 125-138, 2009.

[6] EPZA, Meat Production in Kenya, Export Processing Zones Authority, 2005, http://www.epzakenya.com/UserFiles/File/ MeatIndustry.pdf.

[7] P. Nyaga, Poultry Sector Country Review, FAO Animal health and production Division, 2007, ftp://ftp.fao.org/docrep/fao/ 011/ai379e/ai379e00.pdf.

[8] D. Nierenberg, "A fowl plague," World Watch, vol. 20, no. 1, pp. 24-29, 2007.

[9] M. McCarthy, S. O’Reilly, L. Cotter, and M. De Boer, "Factors influencing consumption of pork and poultry in the Irish market," Appetite, vol. 43, no. 1, pp. 19-28, 2004.

[10] N. E. Tambi, "Testing for habit formation in food commodity consumption patterns in Cameroon," Journal of International Food and Agribusiness Marketing, vol. 10, no. 1, pp. 15-30, 1998.

[11] N. E. Tambi and O. W. Maina, "Patterns of change in beef production and consumption in Africa," Revue Scientifique et Technique, vol. 22, no. 3, pp. 965-976, 2003.

[12] C. L. Delgado, "Rising demand for meat and milk in developing countries: implications for grasslands-based livestock 
production," in Proceedings of the 20th International Grassland Congress, D. A. McGilloway, Ed., Grassland: a Global Resource, Wageningen Academic Publishers, Dublin, Ireland, June 2005.

[13] C. L. Delgado, "Rising consumption of meat and milk in developing countries has created a new food revolution," Journal of Nutrition, vol. 133, no. 11, pp. 3907S-3910S, 2003.

[14] A. Catley, "The growing demand for livestock. Will policy and institutional changes benefit poor people?" ID21 Insights, vol. 72, pp. 1-2, 2008.

[15] WHO, Diets, Nutrition and the Prevention of Chronic Diseases, WHO Technical Report Series 916. Report of a Joint WHO/FAO Expert Consultation, WHO, Geneva, Switzerland, 2003.

[16] P. W. Gerbens-Leenes and S. Nonhebel, "Consumption patterns and their effects on land required for food," Ecological Economics, vol. 42, no. 1-2, pp. 185-199, 2002.

[17] A. C. Costales, U. Pica-Ciamarra, and J. Otte, "Livestock in a changing landscape: social consequences for mixed crop-livestock production systems in developing countries," Research Report. Ref: 07-05, Pro-Poor Livestock Policy Initiative. A Living from Livestock, 2007.

[18] P. Hazell, "All-Africa review of experiences with commercial agriculture: case study on livestock," 2007, http://siteresources. worldbank.org/INTAFRICA/Resources/2579941215457178567/Ch11_Livestock.pdf.

[19] M. W. Rosegrant, S. A. Cline, W. Li, T. B. Sulser, and R. A. Valmonte-Santos, Looking Ahead: Long-Term Prospects for Africa's Agricultural Development and Food Security, 2020 Discussion Paper No. 41, International Food Policy Research Institute, Washington, DC, USA, 2005.

[20] C. L. Delgado, M. W. Rosegrant, H. Steinfeld, S. K. Ehui, and C. Courbois, Livestock to 2020. The Next Food Revolution, Food, Agriculture, and the Environment Discussion Paper 28, IFPRI, Washington, DC, USA, 1999.

[21] P. K. Thornton, "Livestock production: recent trends, future prospects," Philosophical Transactions of the Royal Society B, vol. 365, no. 1554, pp. 2853-2867, 2010.

[22] IAASTD, Agriculture at a Crossroads, Global Report, Edited by B. D. McIntyre, H. R. Herren, J. Wakhungu, R. T. Watson, Island Press, Washington, DC, USA, 2009.

[23] FAO, The State of Food and Agriculture 2010-11, Livestock in a balance, Electronic Publishing Policy and Support Branch Communication Division-FAO, Rome, Italy, 2009.

[24] FAO, "Faostat," 2011, http://faostat.fao.org/.

[25] C. Williamson and M. M. Shah, "Models of expenditure systems for Kenya: International Institute for Applied Systems Analysis," A-2361 Laxenburg Austria, Working Paper, pp. 8171, 1981.

[26] H. Bouis, L. Haddad, and E. Kennedy, "Does it matter how we survey demand for food?. Evidence from Kenya and the Philippines," Food Policy, vol. 17, no. 5, pp. 349-360, 1992.

[27] P. Gamba, Urban Domestic Consumption Patterns for Meat: Trends and Policy Implications, Working Paper No. 17, Tegemeo Institute of Agricultural Policy and Development, Egerton University, 2005.

[28] M. Musyoka, J. Lagat, D. Ouma, T. Wambua, and P. Gamba, "Structure and properties of urban household food demand in Nairobi, Kenya: implications for urban food security," Food Security, vol. 2, pp. 179-193, 2010.

[29] D. Chantylew and A. Belete, "A statistical analysis of demand for beef, mutton/ goat, pork and chicken in kenya, 19611991," Agrekon, vol. 36, pp. 1-11, 1997.

[30] G. P. Juma, M. Ngigi, I. Baltenweck, and A. G. Drucker, "Consumer demand for sheep and goat meat in Kenya," Small Ruminant Research, vol. 90, no. 1-3, pp. 135-138, 2010.
[31] A. Deaton and J. Muellbauer, "An almost ideal demand system," The American Economic Review, vol. 70, pp. 312-326, 1980.

[32] J. M. Alston and J. A. Chalfant, "The silence of the lambdas: a test of the almost ideal and rotterdam models," American Journal of Agricultural Economics, vol. 75, pp. 304-313, 1993.

[33] P. R. Taljaard, Z. G. Alemu, and H. D. van Schalkwyk, "The demand for meat in South Africa: an almost ideal estimation," Agrekon, vol. 43, pp. 430-443, 2004.

[34] A. Abdulai and D. Aubert, "A cross-section analysis of household demand for food and nutrients in Tanzania," Agricultural Economics, vol. 31, no. 1, pp. 67-79, 2004.

[35] T. Y. Sheng, M. N. Shamsudin, Z. Mohamed, A. M. Abdullah, and A. Radam, "Demand analysis of meat in Malaysia," Journal of Food Products Marketing, vol. 16, no. 2, pp. 199-211, 2010.

[36] D. L. Edgerton, "Weak separability and the estimation of elasticities in multistage demand systems," American Journal of Agricultural Economics, vol. 79, no. 1, pp. 62-79, 1997.

[37] J. J. Heckman, "Sample selection bias as a specification error," Econometrica, vol. 47, pp. 153-161, 1979.

[38] D. Heien and C. R. Wessells, "Demand systems estimation with microdata: a censored regression approach," Journal of Business \& Economic Statistics, vol. 8, pp. 365-371, 1990.

[39] R. A. Pollak and T. J. Wales, "Demographic variables in demand analysis," Econometrica, vol. 49, pp. 1533-1551, 1981.

[40] G. Moschini, "Units of measurement and the stone index in demand system estimation," American Journal of Agricultural Economics, vol. 77, pp. 63-68, 1995.

[41] R. Green and J. M. Alston, "Elasticities in AIDS Models," American Journal of Agricultural Economics, vol. 72, pp. 442$445,1990$.

[42] D. J. Hayes, T. I. Wahl, and G. W. Williams, "Testing restrictions on a model of Japanese meat demand," American Journal of Agricultural Economics, vol. 72, no. 3, pp. 556-566, 1990.

[43] StataCorp, Statistical Software: Release 11.1, StataCorp LP, College Station, Tex, USA, 2009.

[44] M. Berndsen and J. V. D. Pligt, "Ambivalence towards meat," Appetite, vol. 42, no. 1, pp. 71-78, 2004.

[45] R. York and M. H. Gossard, "Cross-national meat and fish consumption: exploring the effects of modernization and ecological context," Ecological Economics, vol. 48, no. 3, pp. 293-302, 2004.

[46] B. Lewis, Effect of Household Animal Production on Household Meat Consumption in Rural Bangladesh [Dissertation], University of California, Berkeley, Calif, USA, 2010.

[47] M. H. Gossard and R. York, "Social structural influences on meat consumption," Human Ecology Review, vol. 10, no. 1, pp. $1-9,2003$.

[48] P. H. G. J. De Silva, N. S. B. M. Atapattu, and A. L. Sandika, "A study of the socio-cultural parameters associated with meat purchasing and consumption pattern: a case of Southern Province, Sri Lanka," Journal of Agricultural Sciences, vol. 5, pp. 71-79, 2010.

[49] A. S. Deaton and J. Muellbauer, "On measuring child costs: with applications to poor countries," The Journal of Political Economy, vol. 94, pp. 720-744, 1986.

[50] B. A. Lanfranco, G. C. W. Ames, and C. L. Huang, "Comparisons of Hispanic households' demand for meats with other ethnic groups," Journal of Food Distribution Research, vol. 33, pp. 92-101, 2002.

[51] T. Y. Sheng, M. N. Shamsudin, Z. Mohamed, A. M. Abdullah, and A. Radam, Demand for meat products in Malaysia, MPRA Paper, University Library of Munich, Munich, Germany, 2008. 
[52] M. A. Wadud, "An analysis of meat demand in Bangladesh using the almost ideal demand system," The Empirical Economics Letters, vol. 5, no. 1, 2006.

[53] A. Weliwita, D. Nyange, and H. Tsujii, "Food demand patterns in Tanzania: a censored regression analysis of microdata," Sri Lankan Journal of Agricultural Economics, vol. 5, pp. 10-23, 2003.

[54] N. E. Tambi, "Analysis of household attitudes toward the purchase of livestock products and fish in Cameroon," Agricultural Economics, vol. 26, no. 2, pp. 135-147, 2001.

[55] G. Osho and A. Nazemzadeh, "Consumerism: statistical estimation of Nigeria meat demand," Journal of International Business Research, vol. 4, pp. 69-79, 2005.

[56] H. N. Raghavendra, S. B. Mahajanashetti, N. N. Karnool, V. S. Kulkarni, and H. Basavaraj, "Meat consumption pattern and its preference in Dharwad district: a socio-economic analysis," Karnataka Journal of Agricultural Sciences, vol. 22, pp. 353$358,2009$. 


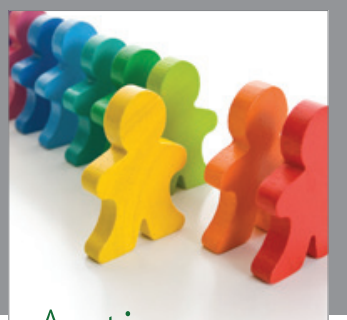

Autism

Research and Treatment
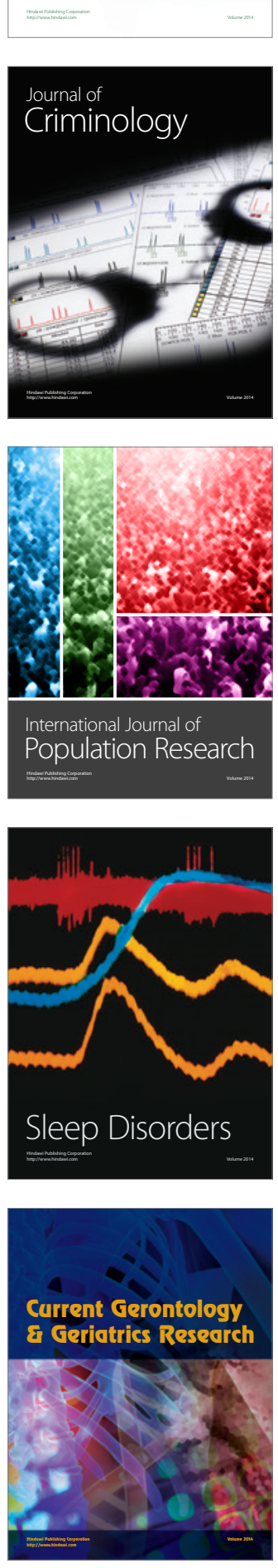
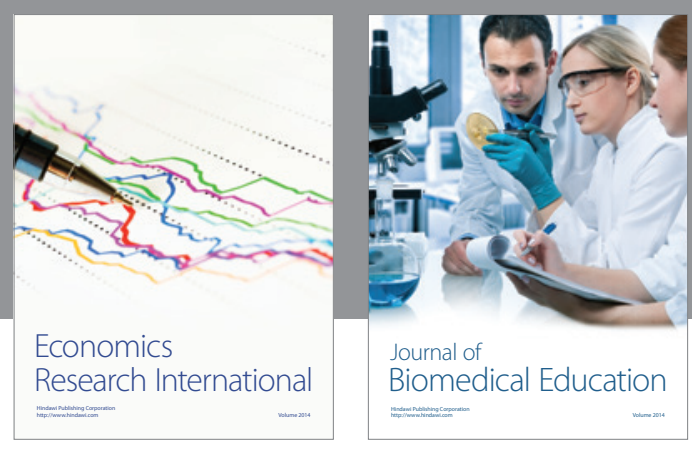

Journal of

Biomedical Education

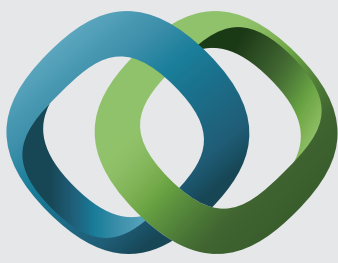

\section{Hindawi}

Submit your manuscripts at

http://www.hindawi.com
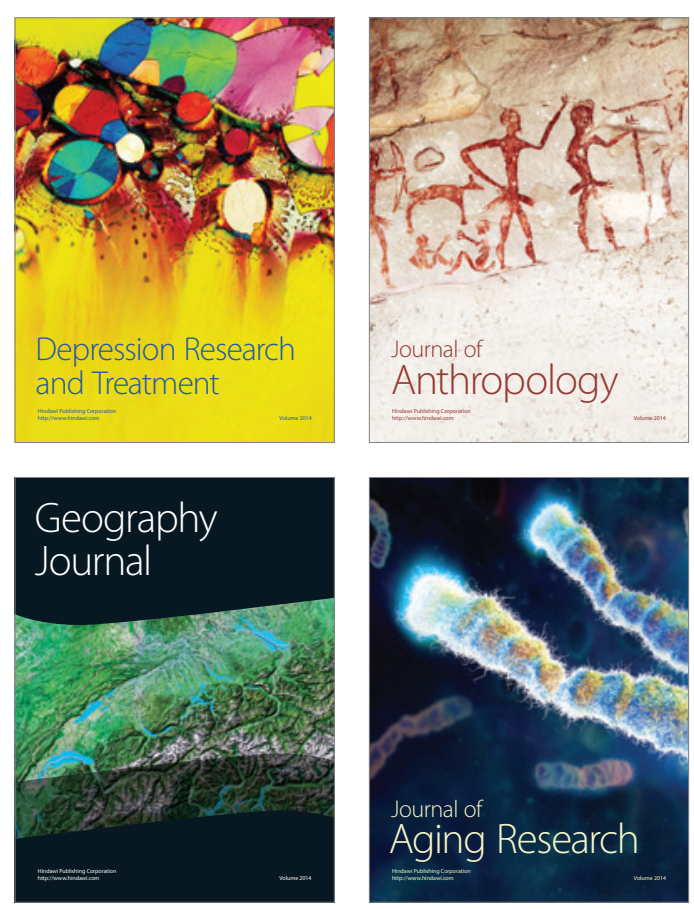

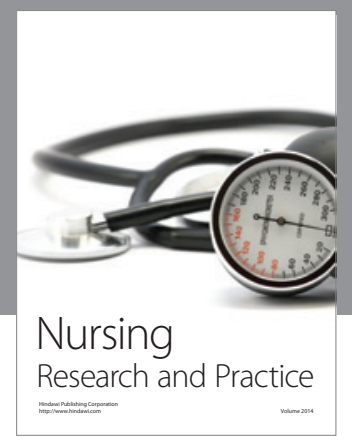

Nursing

Research and Practice

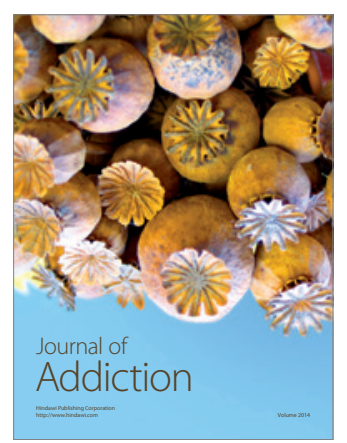

Child Development

Research

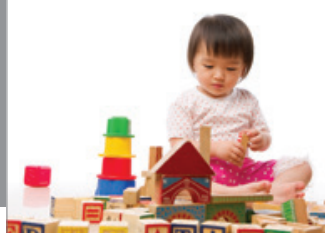

迥
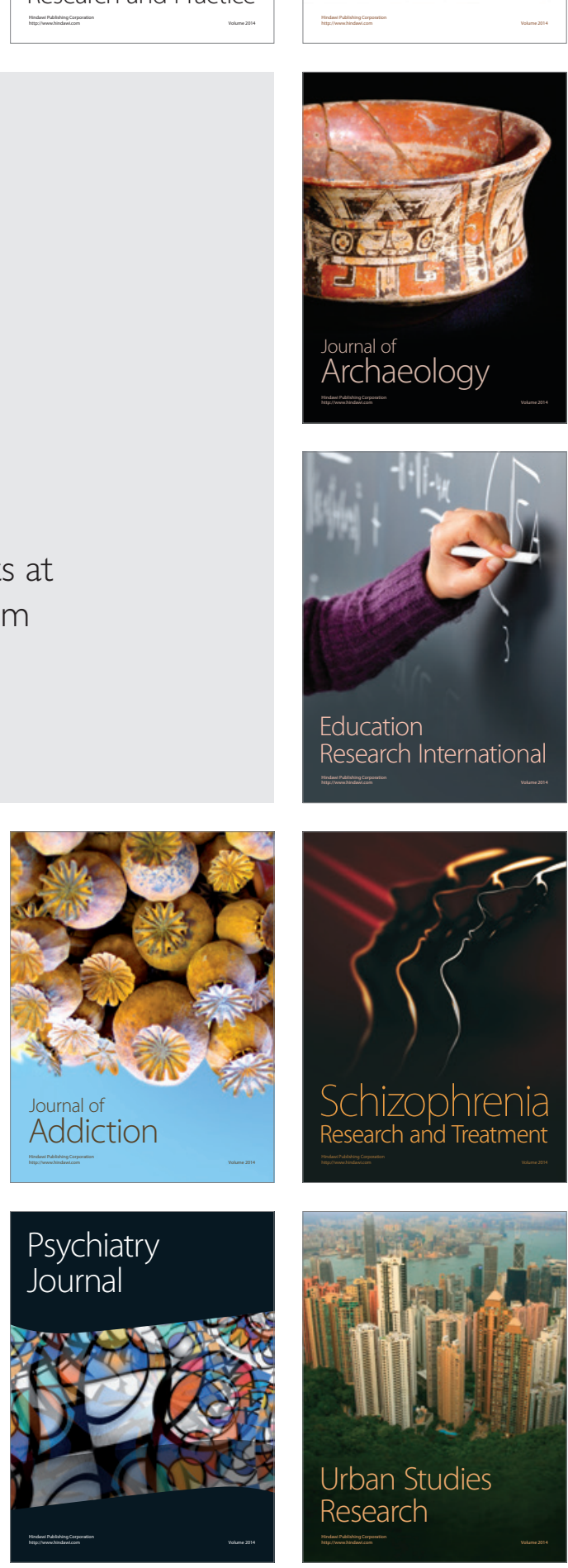